EPJ Web of Conferences 92,02093 (2015)

DOI: $10.1051 /$ epjconf/ 20159202093

(C) Owned by the authors, published by EDP Sciences, 2015

\title{
The Effect of Break Edge Configuration on the Aerodynamics of Anti-Ice Jet Flow
}

\author{
V. Tatar ${ }^{1, a}$, H. Yildizay ${ }^{2}$ and H. $\operatorname{Aras}^{3}$ \\ 1,a Tusaş Engine Industries, Dep. of Aero \& Thermal \& Secondary Air Systems, Eskişehir, Turkey \\ ${ }^{2}$ Research Assistant, Dep. Mechanical Engineering, University of Osmangazi, Eskişehir, Turkey \\ ${ }^{3}$ Prof.Dr., Dep. Mechanical Engineering, University of Osmangazi, Eskişehir, Turkey
}

\begin{abstract}
One of the components of a turboprop gas turbine engine is the Front Bearing Structure (FBS) which leads air into the compressor. FBS directly encounters with ambient air, as a consequence ice accretion may occur on its static vanes. There are several aerodynamic parameters which should be considered in the design of anti-icing system of FBS, such as diameter, position, exit angle of discharge holes, etc. This research focuses on the effects of break edge configuration over anti-ice jet flow. Break edge operation is a process which is applied to the hole in order to avoid sharp edges which cause high stress concentration. Numerical analyses and flow visualization test have been conducted. Four different break edge configurations were used for this investigation; without break edge, $0.35 \mathrm{xD}, 74 \mathrm{xD}, 0.87 \mathrm{xD}$. Three mainstream flow conditions at the inlet of the channel are defined; $10 \mathrm{~m} / \mathrm{s}, 20 \mathrm{~m} / \mathrm{s}$ and $40 \mathrm{~m} / \mathrm{s}$. Shear stresses are extracted from numerical analyses near the trailing edge of pressure surface where ice may occur under icing conditions. A specific flow visualization method was used for the experimental study. Vane surface near the trailing edge was dyed and thinner was injected into anti-ice jet flow in order to remove dye from the vane surface. Hence, film effect on the surface could be computed for each testing condition. Thickness of the dye removal area of each case was examined. The results show noticeable effects of break edge operation on jet flow, and the air film effectiveness decreases when mainstream inlet velocity decreases.
\end{abstract}

\section{Introduction}

This paper presents numerical and experimental investigation of a parameter affecting anti-ice system functionality of FBS part at gas turbine engine. FBS which is located behind intake part is a major component of the gas turbine. Due to its location, ice may accrete on its static vanes under icing conditions. Therefore, antiicing system was designed in order to avoid possible adverse effects of ice accretion. Main purpose of these vanes, each of which has 15 discharge holes located close to the trailing edge, is to lead inlet air to intermediate compressor. Metal is heated by anti-ice air which flows through a channel inside the vane and also air film is provided through vane surface near the trailing edge via these holes. Ice accretion on the vane surface is prevented by providing heat transfer via conduction and convection. Sharp edges which create stress concentration on the hole are formed during manufacturing of these holes; therefore, break edge operation is applied to remove the sharp edges. Break edge operation may cause flow separation by changing exit angle of the jet flow and it reduces film effectiveness on the surface. The break edge dimension has to be limited not to disturb air film. In order to limit the dimension and distinguish the effect of break edge operation, numerical analyses and flow visualization test have been conducted. After preliminary numerical analyses, four break edge operations were determined to be analysed; $0.35 \mathrm{xD}, 74 \mathrm{xD}, 0.87 \mathrm{xD}$ where $\mathrm{D}$ is the diameter of a discharge hole. These configurations were analysed at three main flow inlet velocity conditions, $10 \mathrm{~m} / \mathrm{s}, 20 \mathrm{~m} / \mathrm{s}$ and $40 \mathrm{~m} / \mathrm{s}$. Numerical analysis results were compared in terms of wall shear stress and velocity vector at the exit of the hole. Moreover, flow visualization tests were performed at the same conditions with numerical models. Flow visualization can provide an overall picture of the flow field and there are numerous techniques such as optical, non-optical and special methods [1]. In this study a nonoptical surface dying method which was adapted from available methods was used for experimental flow visualization. Trailing edge of the vane is dyed and thinner is injected into the anti-ice jet flow. Hence, thinner which is discharged from the holes remove the dye from surface and trace of air film can be followed.

\footnotetext{
${ }^{\mathrm{a}}$ Corresponding author: volkan.tatar@tei.com.tr
} 
Thickness of the dye on the metal surface is accepted as proportional to the film effectiveness. Dye removal area due to the anti-ice jet flow was detected and thickness of the each affected area near the trailing edge was recorded. These recordings were compared for all geometries. Holes were grouped in terms of vane profile and icing risk regions. The findings have been analysed and their break edge limits have been determined.

Turbine cooling studies can be examined since physical phenomena are in parallel to the present study. Performance of coolant holes with injection angles of 35 and 55 degree were compared and a decrease film effectiveness for the 55 degree holes of 10 and $30 \%$ for momentum flux ratios of $\mathrm{I}=0.16$ and 0.63 , respectively were found (These results are presented in terms of I because this is expected to be the scaling parameter for jet separation) [2]. Hole injection angles of 35 and 90 degree were tested, and slightly decreased film effectiveness was found for the 90 degree holes at $\mathrm{M}$ $=0.5$, but improved performance was found for the 90 degree holes for a high blowing ratio of $\mathrm{M}=1.4$ [3]. Similar results were found in the study having holes with 30, 60 and 90 degree injection angles. Their results showed about a 30\% decrease in peak $\eta$ values for lower blowing ratios for 90 degree injection compared to 30 degree injection. For higher blowing ratios, $M>1.2$, there was as much as $60 \%$ increase in.$\eta$, but at these high blowing ratios, performance was poor. The increased film effectiveness for 90 degree holes at higher blowing ratios was attributed to more interaction with adjacent jets for 90 degree holes compared to 30 degree holes [4].

Experiments were conducted with row-of-holes injection along a convex and a concave wall at different injection angles. Injection angle effects were found to vary with blowing rate. At low blowing rates, the injection angle is unimportant, while at moderate blowing rates the shallower angles provide better effectiveness, and at higher blowing rates a steeper injection angle may actually provide better results. The counter-rotating vortex motion was considered to explain these effects [5]. The effect of exit angle of the cooling hole with different angles of 30, 45, 90 degrees was explored by using CFD techniques. A realizable k-e model with an emphasis at near-wall functions was used. It is found that lowering the exit angle increases the length of cooling film [6].

Analyses and experimental results show that as break edge dimension is increased, the separation increases as well; however, the film effectiveness decreases. It is observed that lower main inlet velocity increases separation, and effective air film cannot be maintained at the wall surface in selected range.

\section{Numerical Investigations}

Ansys Fluent software was used for the 3D analysis of vanes and wind tunnel test section. There are 15 discharge holes on a vane as a part of anti-ice system and break edge operation is applied to those holes. Numerical domain consists of a vane and the test section of the wind tunnel which is the same as experimental setup shown in
Figure 1.

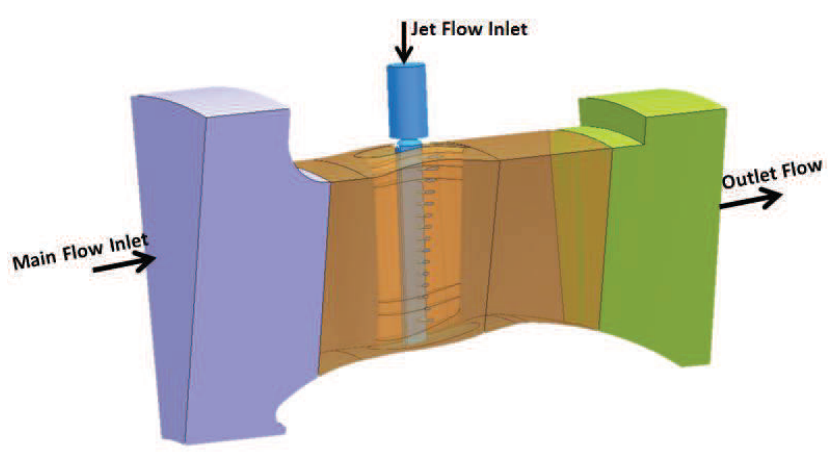

Figure 1. Numerical domain of a vane and test section

Grid of the domain was established in tetrahedral type and it has 13 million cells. Grid configuration is sketched in Figure 2. Especially near the discharge holes, denser mesh was applied to solve velocity field more sensitively and distinguish the differences between the numerical models.

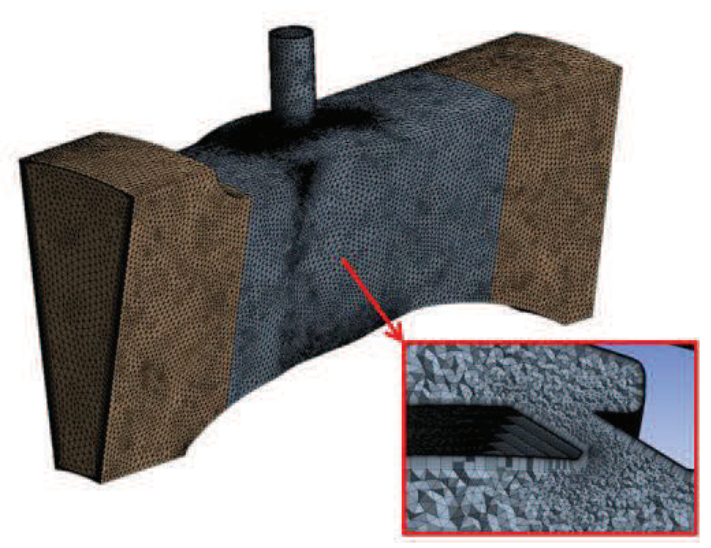

Figure 2. Grid of the numerical domain

Break edge operation on a discharge hole is shown in Figure 3. Break edge configurations were determined and their models were prepared. Break edge configurations have following dimensions;

1. No break edge applied model

2. $0.35 \mathrm{xD}$

3. $0.74 \times \mathrm{D}$

4. $0.87 \times \mathrm{D}$

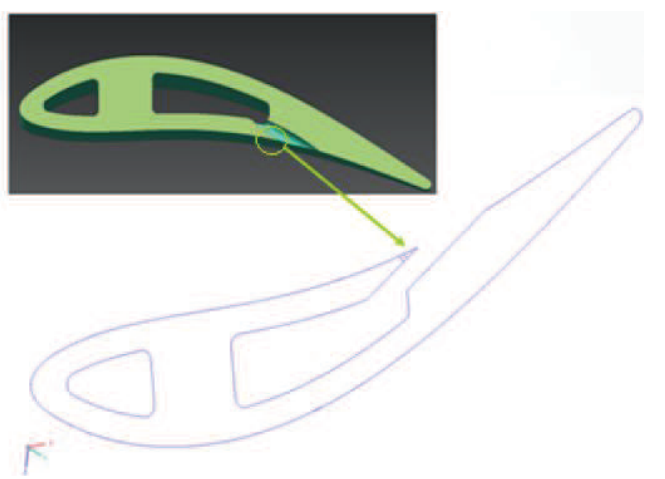

Figure 3. Break edge applied region (cross section of a vane) 
There are number of turbulence models available in the literature for predicting the film effectiveness levels for air film. The most common approach to date is the use of Reynolds-averaged Navier-Stokes (RANS) equations with some type of turbulence model. For RANS-type calculations, two-equation eddy-viscosity models, such as $\mathrm{k}-\varepsilon$ or $\mathrm{k}-\mathrm{w}$ or a second moment closure scheme, such as a Reynolds stress model, are commonly used, each requiring some type of wall treatment. For the wall treatment, two approaches have commonly been used: wall function models or two layer models. While wall function models presume that the flow follows the log law near the wall, the two-layer model eliminates the use of wall functions and divides the flow into a viscosityaffected region and a fully turbulent region. In this study, two-equation realizable k-e turbulence model (Shih et al., 1995) was used with enhanced wall function. To resolve the viscous sublayers, maximum $y+$ of 1.0 was targeted for the first grid point adjacent to all the walls.

In the main and jet flow inlet, average velocity is applied. The channel rigid zones are assumed to be the wall and the surfaces of the channel walls are assumed to be smooth. Periodic conditions are used to side walls to capture pressure gradient better. While velocity inlet is used at the main flow inlet, pressure inlet is used at the jet flow inlet, and pressure outlet condition is used for the exit of the domain.

Three main flow inlet velocity conditions, 10, 20, $40 \mathrm{~m} / \mathrm{s}$ are analysed whereas jet flow inlet pressure is kept constant at 3.14 bars. Analyses are performed for four types of break edge configurations at each main flow inlet conditions. Hence both break edge configuration and main flow effect over flow behaviour can be identified.

\section{Experimental Setup}

The experiments were performed in Istanbul University subsonic wind tunnel. The tunnel is an open circuit type and has a close test section. The size of the rectangular shaped test section is $0.5 \mathrm{~m} \times 0.5 \mathrm{~m} \times 1.2 \mathrm{~m}$. The maximum speed is $40 \mathrm{~m} / \mathrm{s}$. The basic components of the open circuit wind tunnel are intake section, test section, diffuser, exit section, fan, thinner tank, thinner atomizer, screw air compressor and measurement tools. The wind tunnel is shown at the Figure 4.

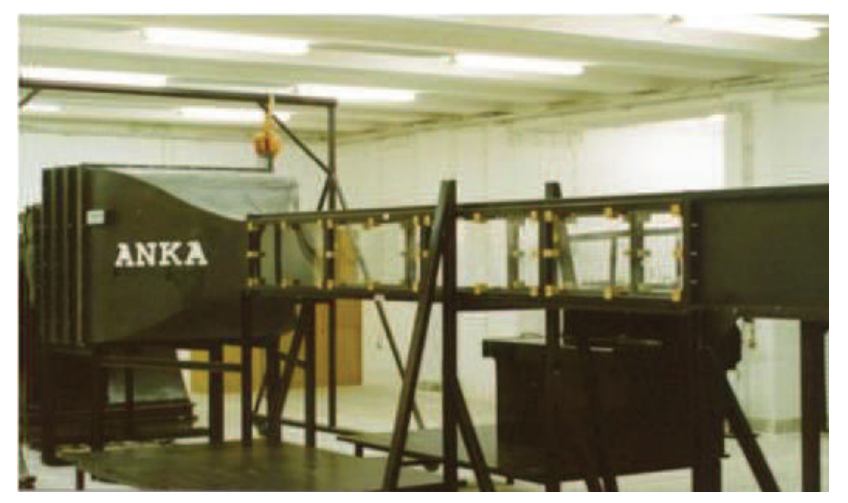

Figure 4. Low speed wind tunnel

\subsection{Components of the Experimental Setup}

Main flow was supplied by a radial fan to the wind tunnel. Jet flow is supplied by a screw air compressor from the top of the vane through inner channel and its capacity is maximum 8 Bars.

There are two regulators; first one controls jet air pressure and the second one controls thinner tank pressure.

Thinner which is injected to jet air in order to remove dye from the vane surface near the trailing edge is stored at thinner tank. Its diameter and height are $120 \mathrm{~mm}, 150 \mathrm{~mm}$, respectively. This tank is pressurized by the screw compressor so that thinner passes through the atomizer.

Compressed jet air and thinner are mixed in the atomizer and thinner is sprayed into the jet flow by means of atomizer.

\subsection{Settlement of the Vanes}

A particular concept was designed for the vane settlement into the wind tunnel. Three vanes were set in the middle of the test section and they are fixed with the connection apparatus (see Figure 5). These vanes are compact and they can be replaced with each other. Test results are taken from the middle vane and the reason for the use of three vanes is to assure passage flows between the vanes. In order not to create vortex in the regions close to the vanes, extra parts were designed, which also represent the working conditions in the engine. The extra parts which enable smooth flow to the vanes are set on and under the vanes.

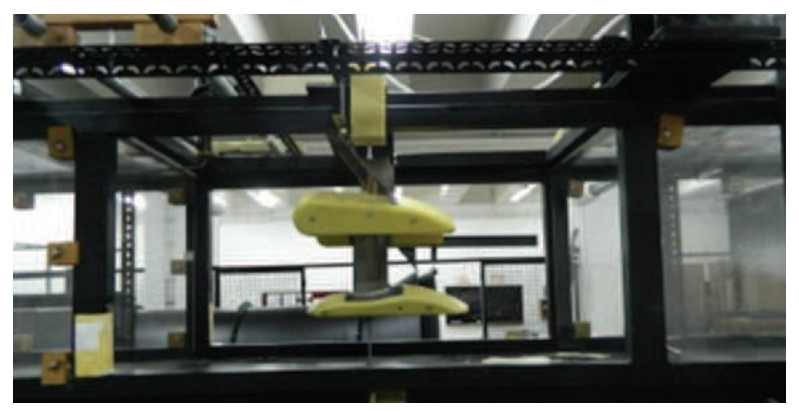

Figure 5. Vane settlement in wind tunnel

Schematic view of the system is shown at the Figure 6.

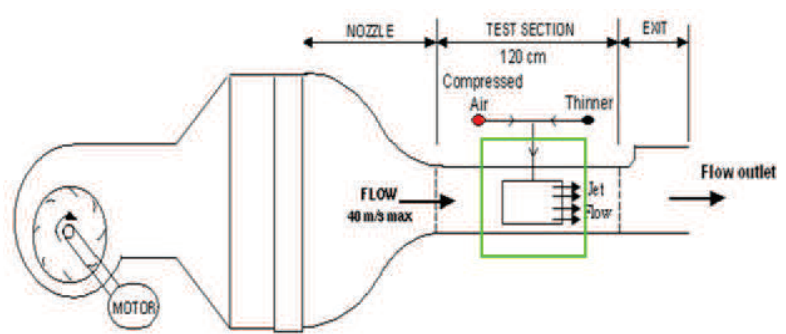

Figure 6. Schematic view of the system 


\section{CFD Analysis Results}

Holes are divided into three groups according to ice accretion on the surface. This grouping makes the analysis of the results easier. First hole is at the tip of the vane and $15^{\text {th }}$. hole is at the hub of the vane. Groups are shown in Table 1.

Table 1. Group of the holes

\begin{tabular}{|c|c|c|c|c|c|}
\hline Hole & Group & Hole & Group & Hole & Group \\
\hline \hline 1 & Grup 1 & 6 & Grup 2 & 11 & Grup 3 \\
\hline 2 & Grup 1 & 7 & Grup 2 & 12 & Grup 3 \\
\hline 3 & Grup 1 & 8 & Grup 2 & 13 & Grup 3 \\
\hline 4 & Grup 1 & 9 & Grup 2 & 14 & Grup 3 \\
\hline 5 & Grup 1 & 10 & Grup 2 & 15 & Grup 3 \\
\hline
\end{tabular}

Analyses results are examined in terms of shear stress and thickness of the affected area along downstream of the hole.

\subsection{Shear Stress Results}

For no-slip wall conditions, Ansys Fluent uses the properties of the flow adjacent to the wall/fluid boundary to predict the shear stress on the fluid at the wall. In laminar flows, this calculation simply depends on the velocity gradient at the wall while in turbulent flows, it depends on one of the approaches among near-wall treatments. In this study, viscosity-affected near-wall region is completely resolved all the way to the viscous sub-layer with enhanced wall treatment.

Shear stress gives clues about the jet flow behaviour. When it increases, there is supposed to be contact between jet flow and wall; otherwise, there would be flow separations. Analyses have been performed for four geometries under three main flow inlet velocity conditions and Table 2 shows their notations. Explanation of the notations is given in Figure 7.

Table 2. Notation of the analyses

\begin{tabular}{|c|c|c|c|}
\hline $\begin{array}{c}\text { Break Edge } \\
\text { Value }(\mathbf{m m})\end{array}$ & $\begin{array}{c}\mathbf{4 0} \\
(\mathbf{m} / \mathbf{s})\end{array}$ & $\begin{array}{c}\mathbf{2 0} \\
(\mathbf{m} / \mathbf{s})\end{array}$ & $\begin{array}{c}\mathbf{1 0} \\
(\mathbf{m} / \mathbf{s})\end{array}$ \\
\hline No Break Edge & A1A & A1B & A1C \\
\hline $0.35 x D$ & A2A & A2B & A2C \\
\hline $0.74 x D$ & A3A & A3B & A3C \\
\hline $0.87 x D$ & A4A & A4B & A4C \\
\hline
\end{tabular}

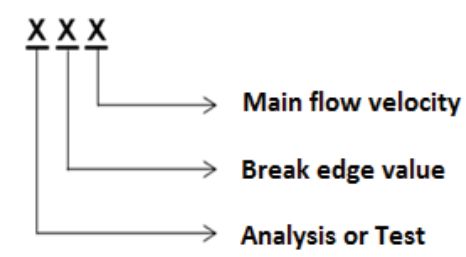

Figure 7. The explanation of the notations

Shear stress graphics along $-\mathrm{x}$ direction through trailing edge are examined for 15 holes. Some findings are summarized below:
- Shear stress values of group 1 are higher than the others due to concave vane profile. Jet flow smoothly flows through the wall surface.

- Higher break edge dimension causes more shear stress on the wall for the group 1. It could be claimed that break edge has positive effect at this region.

- Higher break edge dimension causes less shear stress on the wall at the group 2 and group 3 except the holes 14 and 15. At these holes break edge has slightly positive effect on the shear stress according to the analysis result. - Shear stress is high at the exit of the hole. It decreases and becomes stable along the $-\mathrm{x}$ direction. After reattachment point, it slightly increases.

\subsection{Thickness of the Affected Area}

Thickness of the affected area near the trailing edge is obtained from the analyses. Especially temperature plot can be used to compare the thickness.

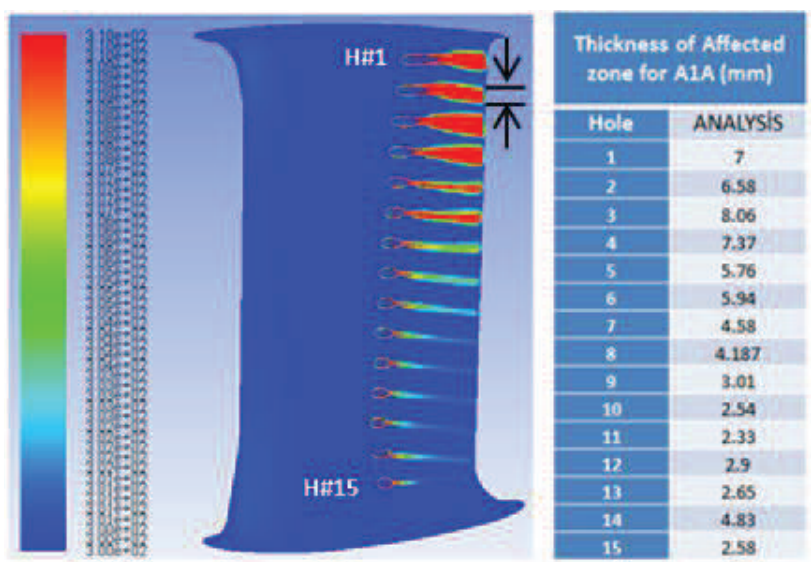

Figure 8. Thickness of the affected area near the trailing edge

Temperature plot is shown in Figure 8 and gradient points are taken into consideration to define thicknesses. Affected zone is high at the first 6 holes and it decreases through the hub of the vane. If the thickness decreases, ice can accrete on the trailing edge, resulting in film air separation from the surface which has been already experienced at the icing rig tests.

\section{Experimental Results}

Flow visualization tests have been performed according to the conditions given in Table 3 which is similar to the analyses conditions. A test takes 30 minutes and each test repeated three times to assure repeatability. A standard procedure was followed during these tests. Trailing edge of the test piece was dyed and placed to the test section. Test piece was digitally photographed once the test finished. 
Table 3. Notation of the tests

\begin{tabular}{|c|c|c|c|}
\hline $\begin{array}{c}\text { Break Edge } \\
\text { Value (mm) }\end{array}$ & $\begin{array}{c}\mathbf{4 0} \\
(\mathbf{m} / \mathbf{s})\end{array}$ & $\begin{array}{c}\mathbf{2 0} \\
(\mathbf{m} / \mathbf{s})\end{array}$ & $\begin{array}{c}\mathbf{1 0} \\
(\mathbf{m} / \mathbf{s})\end{array}$ \\
\hline No Break Edge & $\mathrm{T} 1 \mathrm{~A}$ & $\mathrm{~T} 1 \mathrm{~B}$ & $\mathrm{~T} 1 \mathrm{C}$ \\
\hline $0.35 \mathrm{xD}$ & $\mathrm{T} 2 \mathrm{~A}$ & $\mathrm{~T} 2 \mathrm{~B}$ & $\mathrm{~T} 2 \mathrm{C}$ \\
\hline $0.74 \mathrm{xD}$ & $\mathrm{T} 3 \mathrm{~A}$ & $\mathrm{~T} 3 \mathrm{~B}$ & $\mathrm{~T} 3 \mathrm{C}$ \\
\hline $0.87 \mathrm{xD}$ & $\mathrm{T} 4 \mathrm{~A}$ & $\mathrm{~T} 4 \mathrm{~B}$ & $\mathrm{~T} 4 \mathrm{C}$ \\
\hline
\end{tabular}

Figure 9, 10, 11 shows test results regarding the conditions given in Table 3 .
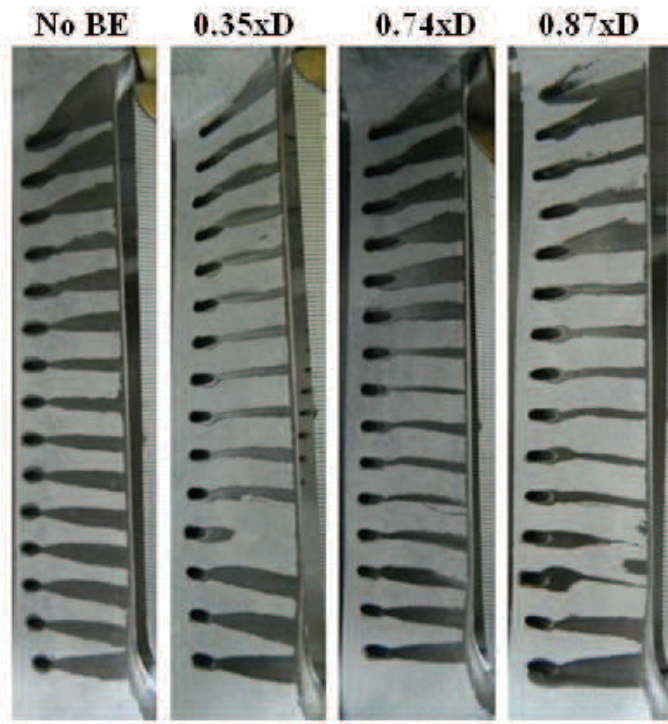

Figure 9. Test result for $10 \mathrm{~m} / \mathrm{s}$ of main flow

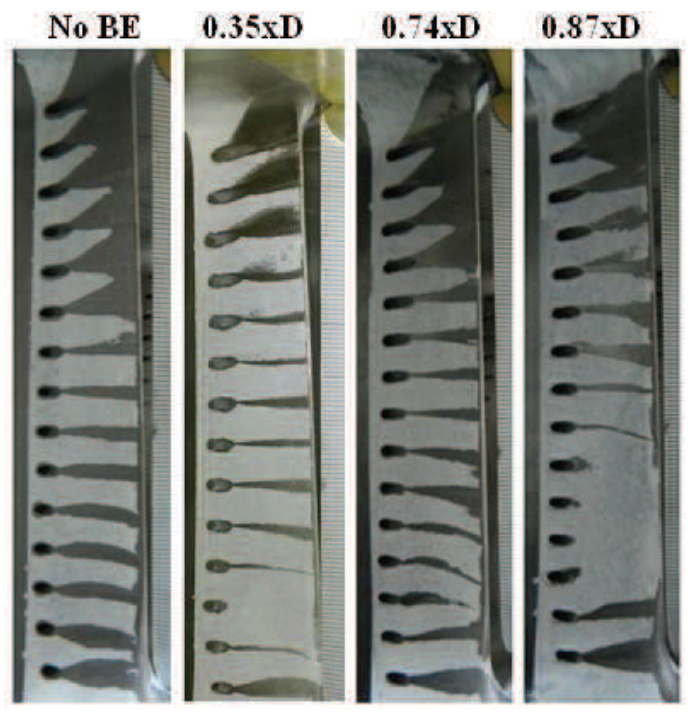

Figure 10. Test result for $10 \mathrm{~m} / \mathrm{s}$ of main flow

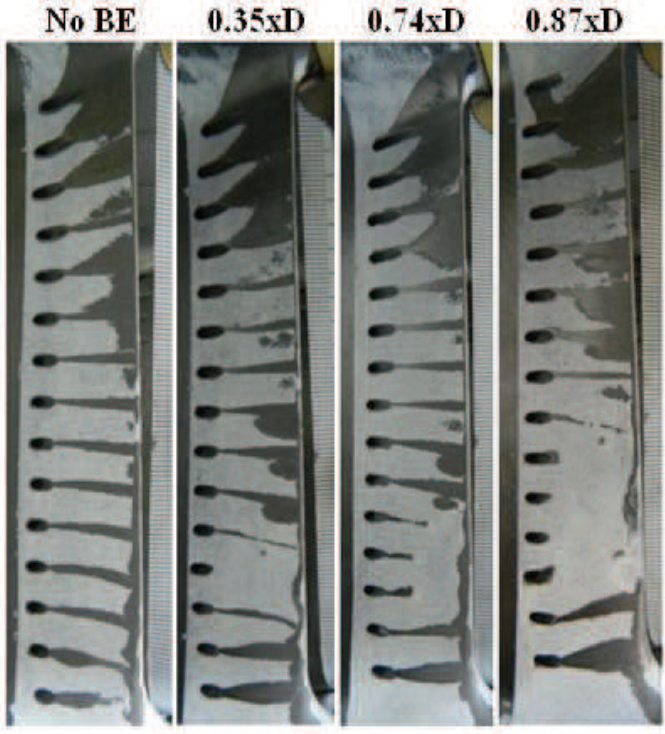

Figure 11. Test result for $10 \mathrm{~m} / \mathrm{s}$ of main flow

\section{Conclusions}

The effect of break edge operation over the jet flow and main flow interaction were investigated by using specific flow visualization method. Jet flow on the trailing edge was traced comparatively for four different configurations. Moreover, three main flow velocity inlet conditions were investigated. Numerical analyses were also performed to provide detailed information about the physics of the flow field.

While the break edge dimension increases, jet flow separates from the surface and air film cannot be maintained. Jet flow at the first group holes sweep out vane surface effectively because of the vane's concave profile. Therefore, the first group has less risk in terms of the ice accretion compared to the other groups. The second group is more sensitive to the dimension. Thickness of the traced area decreases and even loses air film on the surface. For the third group, jet air also cannot be maintained when break edge dimension is increased. It is assumed that thinner exits from the last two holes of the third group due to gravity effect. This assumption is supported by CFD analyses and air film effect would be less effective than test results.

\section{Acknowledgment}

This paper was written with the support of the research project of Eskişehir Osmangazi University. Authors would like to thank Tusaş Engine Industries (TEI) for granting permission to publish this paper.

\section{References}

1. Ristić, S., Scientific Technical Review, Vol.LVII, No.1, (2007) 
2. Kohli, A., and Bogard, D., J. Turbomach., Vol. 119, pp. 352-358, (1997)

3. Foster, N.W., and Lampard, D., J. Eng. Power, Vol. 102, pp. 584-588, (1980)

4. Baldauf, S., Scheurlen, M., Schulz, A., and Wittig, S., J. Turbomach., Vol. 124, pp. 686-698, (2002)

5. Goldstein, R.J. and Stone, L.D., ASME J. Turbomach., Vol. 119, pp. 574-579, (1997)

6. Ky V., Steady State Heat Transfer of a Flat Plate with Cooling Hole in a High Temperature Environment, Master Thesis (2008) 